\title{
Implementação e Análise de Desempenho de um Sistema OFDM com Hardware de Baixo Custo
}

\author{
Eder de Souza, João Dias e Demerson N. Gonçalves
}

Resumo-Com o objetivo de analisar a viabilidade de implementação de elementos de novos sistemas de comunicação sob uma abordagem SDR, este trabalho apresenta a prototipagem de um enlace de comunicação OFDM usando a ferramenta de código aberto GNU Radio e interface de hardware de baixo custo com HackRF One e RTL-SDR. Resultados preliminares se mostraram promissores, permitindo a concepção e teste de sistemas de comunicação digital de uma forma prática e levando em consideração a real condição do canal e deficiências do frontend.

Palavras-Chave-Prototipagem, OFDM, SDR.

Abstract-In order to analyze the feasibility of implementing elements of new communication systems under an SDR approach, this work presents the prototyping of an OFDM communication link using the GNU Radio open source tool and low cost hardware interface with HackRF One and RTL-SDR. Preliminary results have shown promise, allowing the design and testing of digital communication systems in a practical way and taking into account the real condition of the channel and deficiencies of the front-end.

Keywords-Prototyping, OFDM, SDR.

\section{INTRODUÇÃO}

Novas aplicações de baixa latência, grande densidade de conexão e conectividade onipresente requerem um sistema de comunicação eficiente e flexível, uma vez que as características das camadas físicas (PHY) e de acesso ao meio (MAC) afetam o desempenho geral do sistema em termos de eficiência energética, eficiência espectral, throughput alcançável, qualidade de serviço (QoS), etc [1]. Por outro lado, a prototipagem de um sistema de comunicação precisa ser flexível de modo que possa ser capaz de dar suporte a novos algoritmos e testar diferentes formas de uso. O rádio definido por software (SDR) é uma abordagem atraente para prototipagem flexível de sistemas de comunicação onde a funcionalidade dos sistemas depende do software implementado em um dispositivo programável [2].

Em muitos trabalhos tem-se visto o uso do USRP para prototipagem de sistemas de comunicação. Porém, o modelo mais barato (N200) desse SDR custa US\$2.385,00 a unidade [3]. Enquanto o custo total (SDRs para transmissão e recepção, mais as antenas) gasto neste trabalho é de menos de US\$ 200,00 .

O objetivo deste trabalho é apresentar a implementação de um enlace de comunicação usando o processador de um laptop padrão para as funções de banda base digital e o HackRF

Eder de Souza, Engenharia Eletrônica, Cefet/RJ, Rio de Janeiro - RJ, e-mail: ederoliveira@id.uff.br; João Dias, Departamento de Engenharia de Telecomunicações, Cefet/RJ, Rio de Janeiro - RJ, e-mail: joao.dias@cefetrj.br; Demerson N. Gonçalves, Coordenação de Licenciatura em Matemática, Cefet/RJ, Petrópolis - RJ, e-mail:demerson.goncalves@cefet-ri.br.
One e RTL-SDR como hardware para RF. O sistema usa a técnica de transmissão por divisão de frequências ortogonais (OFDM). Como camada de software, foi usado o GNU Radio, um conjunto de bibliotecas de código aberto escrito em $\mathrm{C}++$ e Python.

O restante do trabalho está dividido da seguinte forma: o modelo do sistema de comunicação OFDM é apresentado na seção II; na seção III é apresentada a implementação SDR deste modelo; na seção IV são apresentados alguns resultados de desempenho da prototipagem realizada; na seção V são feitas as conclusões do trabalho.

\section{Modelo do Sistema}

OFDM é um esquema de modulação multiportadora baseada na divisão do fluxo serial de dados em grupos paralelos de fluxos que são transmitidos em subportadoras ortogonais. Quando um sinal OFDM atravessa um canal dispersivo no tempo ou seletivo em frequência, as subportadoras são afetadas apenas por um canal constante ou plano na frequência. Nesse tipo de canal, o sinal pode ser distorcido por interferência intersimbólica (ISI). Este problema é resolvido no OFDM inserindo uma cópia da última parte do símbolo, também conhecida como prefixo cíclico (CP), no início, para absorver os espalhamentos de atraso de canal. O sinal CP-OFDM pode ser expresso no domínio do tempo por [4]

$$
x[n]=\sum_{k=0}^{K-1} s_{k} e^{j 2 \pi \frac{k}{K} n},
$$

onde $s_{k}$ é o símbolo de dados na $k$ - ésima subportadora e $K$ é o número de subportadoras no símbolo OFDM. O sinal na entrada do receptor pode ser escrito por

$$
y=x * h+\omega,
$$

onde $y \in \mathbb{C}^{\left(K+C P+N_{p}-1\right) \times 1}, C P$ é o comprimento do prefixo cíclico e $N_{p}$ é o número de percursos considerado no canal, $x \in \mathbb{C}^{(K+C P) \times 1}, h \in \mathbb{R}^{\left(N_{p}\right) \times(1)}$ é a resposta ao impulso do canal, $*$ é a operação de convolução e $\omega \in \mathbb{C}^{\left(K+C P+N_{p}-1\right) \times 1}$ é o ruído aditivo Gaussiano branco (AWGN).

O sinal recebido no domínio da frequência pode ser escrito como

$$
\bar{s}=\mathbf{F} y
$$

em que $\mathbf{F}$ é a matriz da transformada discreta de Fourier (DFT) unitária de dimensão $K \times K$. 


\section{PRototipAGEM SDR DO SISTEMA}

Nesta seção é detalhada a implementação do sistema usando placas de interface HackRF One, RTL-SDR e a ferramenta de código aberto GNU Radio através de sua interface gráfica GNU Radio Companion (GRC).

\section{A. Hardware empregado}

Foram utilizados os seguintes módulos:

- Dois laptops com sistemas operacionais Linux e Windows, ambos com GNU Radio instalado. Um atuando como transmissor e o outro como receptor.

- Um HackRF One com as seguintes características: Frequência de operação de $1 \mathrm{MHz}$ a $6 \mathrm{GHz}$; Transceiver Half-Duplex; 8 bits de resolução para amostragem; Taxa de amostragem de até $20 \times 10^{6}$ amostras/segundo.

- Um RTL-SDR com as seguintes características: Frequência de operação de $24 \mathrm{MHz}$ a $1766 \mathrm{MHz}$; Dispositivo apenas para recepção; 8 bits de resolução para amostragem; Taxa de amostragem de até $2,56 \times 10^{6}$ amostras/segundo.

\section{B. Descrição da simulação}

O esquema GRC contendo os blocos de construção do transmissor e receptor OFDM é mostrado na Fig.1. A Figura 2 mostra a implementação física usada na análise de desempenho.

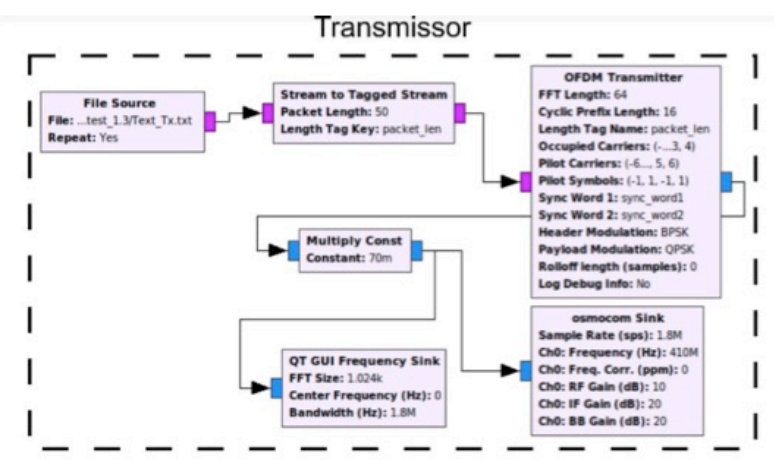

\section{Receptor}

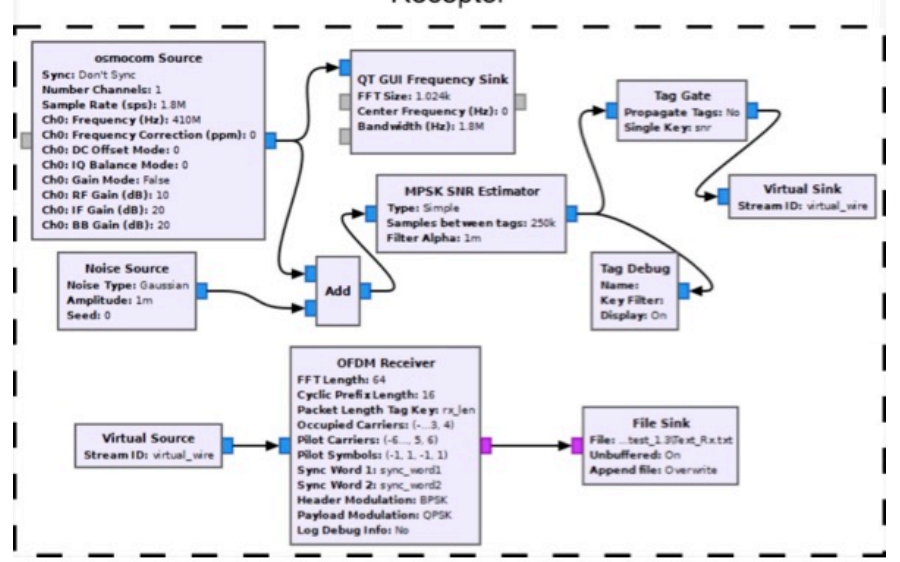

Fig. 1. Esquema GRC dos blocos transmissor e receptor

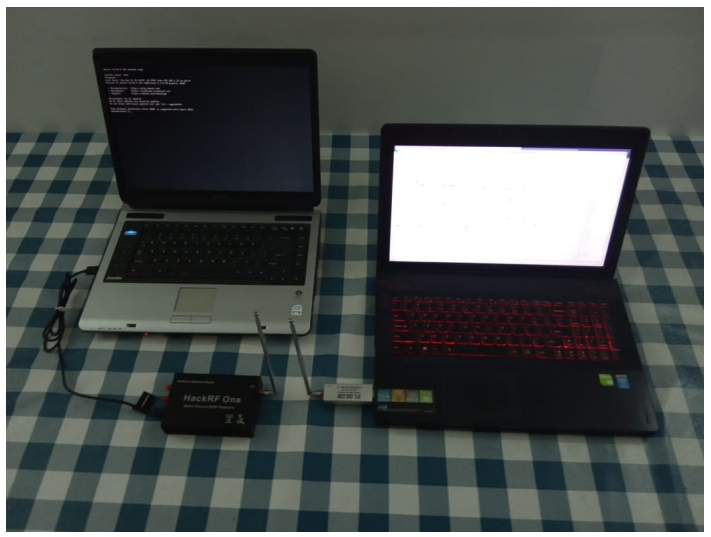

Fig. 2. Implementação física

\section{Simulações e Resultados}

Para validar a prototipagem proposta e analisar seu desempenho com a implementação física foram considerados os parâmetros de simulação mostrados na tabela I:

TABELA I

PARÂMETROS DAS SIMULAÇÕES

\begin{tabular}{|l|c|}
\hline \hline número de subportadoras [K] & 64 \\
\hline modulação das subportadoras & BPSK e QPSK \\
\hline prefixo cíclico em $\mathrm{n}^{\mathrm{o}}$ de subportadoras & 16 \\
\hline subportadoras ocupadas & $(-4,-3,-2,-1,1,2,3,4)$ \\
\hline subportadoras pilotos & $(-6,-5,5,6)$ \\
\hline símbolos pilotos & $(-1,1,-1,1)$ \\
\hline \hline
\end{tabular}

Foi realizada a transmissão de uma mensagem de 50 bytes repetidas vezes com uma potência irradiada pela antena trasmissora de $-23 \mathrm{dBm}$. Na entrada do receptor, o sinal recebe um ganho de $30 \mathrm{~dB}$ em RF mais $20 \mathrm{~dB}$ em banda base, sendo realizada a medida da potência na saída do primeiro bloco do receptor. Variando a distância entre as antenas de 1 a 8 metros e adicionando ruído AWGN a partir de $1 \mathrm{mV}$ de amplitude até o limiar de recepção, foi observado que o receptor recuperou precisamente a mensagem até a distância de 5 metros e o limiar de aproximadamente $8 \mathrm{~dB}$ de relação-ruído.

\section{Conclusões}

No presente trabalho foi implementado um caso simples para servir como introdução para a construção de soluções mais sofisticadas voltadas para sistemas 5G e IoT. Com base nos conceitos do OFDM, foi testado que o HackRF One e o RTL-SDR permitem projetar sistemas flexíveis e escaláveis, capazes de adaptarem-se a diversos sistemas de comunicação e novas aplicações com um custo, aproximadamente, 25 vezes menor que o seu concorrente USRP N200.

\section{REFERÊNCIAS}

[1] Y. Mehmood, N. Haider, M. Imran, A. Timm-Giel, M. Guizani, M2M Communications in 5G: State-of-the-Art Architecture, Recent Advances, and Research Challenges, IEEE Communications Magazine, 2017.

[2] M. Braun, OFDM - You're looking fantastic these days, GNU Radio Conference, Boston, 2013.

[3] https://www.ettus.com/all-products/un200-kit. Visitado em 10/08/2021.

[4] N. Marchetti, M. I. Rahman, S. Kumar, R. Prasad, "New Directions in Wireless Communications Research", cap. 2, OFDM-Principles and Challenges, 2009. 